\title{
The Effects of Learning Activities on Waste and Sewage Management Using Question and Problems-Based Learning for Undergraduate Students of Mahasarakham University, Thailand
}

\author{
Uraiwan Praimee \\ Faculty of Environment and Resource Studies, Mahasarakham University \\ Kham Riang, Kantharawichai District, Maha Sarakham 44150 \\ Tel: 66-830-781-208Ｅ-mail: Praimee_ta@hotmail.com \\ Wannasakphijit Boonserm (Corresponding author) \\ Faculty of Environment and Resource Studies, Mahasarakham University \\ Kham Riang, Kantharawichai District, Maha Sarakham 44150 \\ Tel: 66-922-572-531_E-mail: eiddy101@hotmail.com
}

Received: January 31, 2021 Accepted: February 28, $2021 \quad$ Published: March 12, 2021

doi:10.5296/jei.v7i1.18267 URL: https://doi.org/10.5296/jei.v7i1.18267

\begin{abstract}
In this study, the purposes of this research were to study and compare knowledge about waste and sewage management, environmental ethics and environmental volunteers using question and problems-based learning, before and after class of undergraduate students, to compare knowledge about waste and sewage management, environmental ethics and the environmental volunteers of undergraduate students with different gender and Grade Point Average (GPA). The sample used in the research were 111 undergraduate students being selected by purposive sampling who were enrolled in the course control waste and sewage in the $1^{\text {st }}$ semester of the academic year 2019. The research tools were a learning activity plans on solid waste and sewage management using question and problems-based learning, knowledge test on waste and sewage management, environmental ethics test and environmental volunteers test. The statistics used in the research were frequency, percentage, mean, standard deviation, including hypothesis testing using t-test, F-test (One-Way
\end{abstract}


MANOVA, One-Way MANCOVA) and Univariate Test. The results showed that: (1) The undergraduate students had an average score of knowledge about waste and sewage management, environmental ethics and environmental volunteers in the posttest was higher than the pretest statistical significance $(\mathrm{p}<.05)$; (2) There was no different of knowledge score of waste and sewage management, environmental ethics and environmental volunteers of undergraduate students with different gender ( $p>.05)$; (3) There was statistical significant different of knowledge score of waste and sewage management, environmental ethics and environmental volunteers of undergraduate students with different Grade Point Average $($ GPA) $(\mathrm{p}<.05)$.

Keywords: Learning activity plans, Waste and sewage management, Question based learning, Problem-based learning, Knowledge, Environmental ethics, Environmental volunteers

\section{Introduction}

Garbage problem is a major problem that tends to become more serious which is caused by the increase in the population. Economic expansion and advancement in technology are thus invention and develop more human facilities causing the nature of daily life to change causing a large amount of waste especially in large cities and communities where the nature or composition of the garbage changes according to the civilization and the nature of the daily lifestyle of the people. The problem of waste or garbage is an important reason to cause problems such as air pollution, water pollution, disease vectors and make the scenery not beautiful. Currently, the management of solid waste in Thailand has declared a national agenda powered by the roadmap and the relevant agencies, both government and private and the public to participate in the operation of waste management. In addition, the National Solid Waste Management Master Plan (2016-2021) has been developed to resolve the solid waste problem in accordance with the government policy. The concept is focused on reducing waste at the source, reuse and take advantage of new principles 3Rs (The Secretariat of the House of Representatives, 2019). Thailand's current focus is the development of social learning by giving the people of the country knowledge to be able to access to and dissemination of knowledge leads to creativity to develop and create wealth for the country. Therefore, teaching and learning in the present age must be taught and taught to achieve learning. Therefore, teaching and learning in the present must be taught to create learning. So that the learners have knowledge able to develop themselves according to the potential of the learners by focusing on learner or learner-centred with a teacher to guide, give opinions, give advice. In particular, higher education institutions are organizations responsible for higher education in order to produce quality graduates to serve society and the labour market as an instructor responsible for teaching students directly. So, it is important that mechanisms are to encourage higher education institutions to achieve such functions effectively. Teachers' learning management cannot use a single lecture-based learning process. But have to choose a variety of teaching methods to encourage students to seek additional knowledge from books, textbooks or learning resources in the community. This will help students to achieve complete learning and create desirable behaviours or characteristics in students relatively permanently (Patcharee, 2008). 
For the development of learning to encourage learners to think, analyze, solve problems by using problem-based learning. It is a learning style that provides learners with critical thinking and problem solving skills based on understanding and problem solving (Yosawee, 2011). The integration with question-based learning is the learning using questions. It is a learning process aimed at developing the cognitive processes of the learners. The instructors will enter the question in a way that is a good question. The students can develop ideas, asking for learners to use rational, analytical, critical, synthetic, or valuation thinking to answer them (Pimpan, 2002). One important element of teaching and learning is the instruction manual or plans for various learning activities, which will be a tool to transfer knowledge to learners to achieve the achievement of the goals of teaching and learning effectively especially the Bachelor of Science program, Environmental Education, Faculty of Environment and Resource Studies, Mahasarakham University. This is a course aimed at developing undergraduates with knowledge, attitudes, awareness, skills in problem solving and participation in solving environmental problems and also able to be a leader and disseminate knowledge properly and to develop the quality of education at the under graduates level according to curriculum. For that reason, this research will focus on developing learning activities on waste and sewage management by using question and problems-based learning integration with environmental education principles to provide undergraduate students with knowledge and understanding on waste and sewage management to have environmental ethics and volunteers to be able to apply the knowledge gained in daily life leading to further participation in environmental responsibility.

\section{Method}

\subsection{Research Conceptual Framework}

The development of learning activities on waste and sewage management using question and problems-based learning is the integration of learning activities using the question-based learning together with the problem-based learning that the researcher has applied from the Office of the Education Council (2007) and the theory of Pimpan (2002). It consists of 5 steps, Step 1: Formulate the problem, Step 2: Ask the cause and effect, Step 3: Discussion for answers, Step 4: Synthesize problems and answers, and Step 5: Summary of the lesson by organizing as a learning activity consisting of 7 learning activity plans : general solid waste management, organic waste management, recycling waste management, hazardous waste and electronic waste management, sanitary landfills management, RDF-waste power plant and master plan for solid waste management of the country (2016-2021). The research tool was a learning activity plans on waste and sewage management, knowledge test, environmental ethics test and environmental volunteers test using the tools created to consult with an advisors, then send 5 experts to determine the consistency of the communication and evaluation tools, after that try out with undergraduate students who are not sample. Then organized learning activities on waste and sewage management using question and problems-based learning for 111 undergraduate students were selected from purposive sampling who were enrolled in the course control garbage and sewage in the $1^{\text {st }}$ semester of the academic year 2019, to provide students with knowledge about waste and sewage management, environmental ethics and environmental volunteers. As shown in Figure 1. 


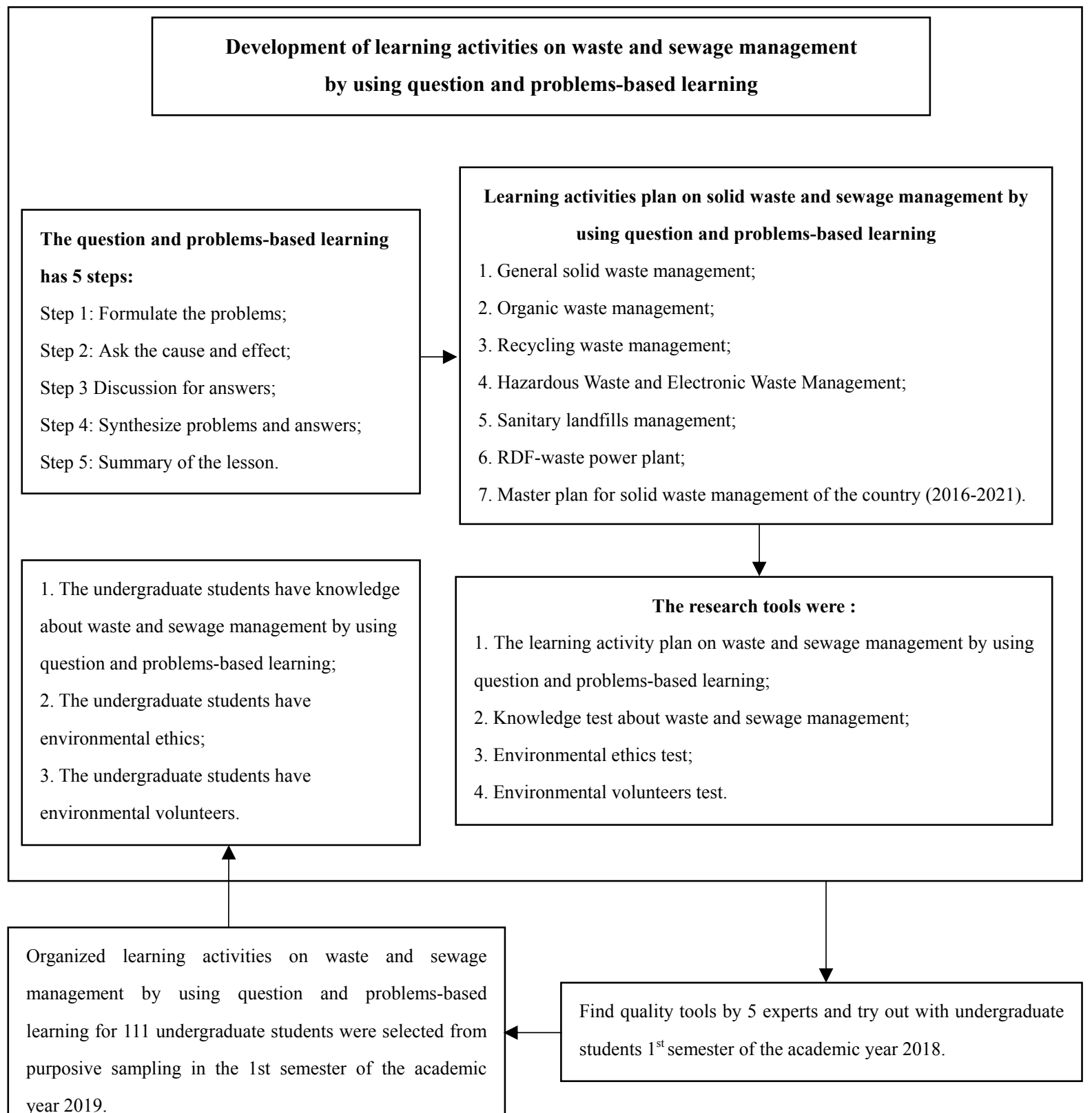

Figure 1. Research conceptual framework

\subsection{Population and Sample}

The population used in this research were 374 undergraduate students in years 1-4 in Environmental Education program, Faculty of Environment and Resource Studies, Mahasarakham University in the $1^{\text {st }}$ semester of the academic year 2019.

The Sample used in the research were 111 undergraduate students in Environmental Education program, Faculty of Environment and Resource Studies, Mahasarakham 


\section{Macrothink

University in the $1^{\text {st }}$ semester of the academic year 2019, which were derived from purposive sampling in control garbage and sewage course.

\subsection{Variables}

The independent variables were learning activities plans on waste and sewage management using question and problems-based learning, gender and Grade Point Average (GPA) of sample students.

The dependent variables were knowledge about waste and sewage management using question and problems-based learning, environmental ethics and environmental volunteers.

\subsection{The Research Tools and Checking Tools' Quality}

The research tools and checked for quality tools which can be divided into 2 categories:

2.5.1 The tools used in the transmission were learning activities plan on waste and sewage management using question and problems-based learning with the following steps:

(1) Study details of the Bachelor of Science program, Environmental Education , Faculty of Environment and Resource Studies, Mahasarakham University to analyze goals, objectives and content to create a plan of learning activities.

(2) Study principles and methods for creating a learning activity plans on waste and sewage management by using question and problems-based learning by studying the concepts, theories, documents and related research to determine the content in accordance with the curriculum and course descriptions, control waste and sewage.

(3) The researcher has developed a preliminary course content framework to take experts to examine and make recommendations about contents of 7 activities plans as shown in Figure 1 .

(4) Take the learning activities plan created for 5 experts to consider and examine the appropriate content in developing the learning activity plan.

(5) Bring the results of the evaluation 5 experts analyzed the consistency of content (Index of item Objective Congruence: IOC). It showed that the IOC was 0.92 and the validity was 4.42. Showed that the learning activities was the most appropriate level.

(6) Improve the learning activities plans according to expert recommendations. Then, try out with the $4^{\text {th }}$ year undergraduate students in Environmental Education program, Faculty of Environment and Resource Studies, Mahasarakham University in the $1^{\text {st }}$ semester of the academic year 2018 .

(7) Improve the learning activities plans, then lead learning activities plans used with 111 undergraduate students in Environmental Education program, Faculty of Environment and Resource Studies, Mahasarakham University in the $1^{\text {st }}$ semester of the academic year 2019, which were derived from purposive sampling in control garbage and sewage course. 
2.5.2 The tools used in the measurement and evaluation, including the knowledge test about waste and sewage management using question and problems-based learning, environmental ethics test and environmental volunteers test the details are as follows:

(1) Create a knowledge test about waste and sewage management by studying principles and methods for creating knowledge tests from related documents, books and research. It is 70 items of multiple choice, 4 options A, B, C and D to choose only one correct answer. The criteria for correct answer gave 1 point, wrong answer gave 0 points, the criteria for interpreting the points are as follows on Boonchom (1990). It showed that the average score was 0.00-13.99 means that the students have the least level of knowledge, the average score was 14.00-27.99 means that the students have a low level of knowledge, the average score was 28.00-41.99 means that students have moderate knowledge, the average score was 42.00-55.99 means that the student's knowledge was at a high level and the average score was 56.00-70.00 means that students have the knowledge at the highest level.

(2) For environmental ethics test, there are 35 items of 4 options which are A, B, C and D. There are 4 levels set by the ethical rating as follows on Prayoon (2016). Level 1: average score 1.00-1.75 for myself; Level 2: average score 1.76-2.50 for the relatives and friends; Level 3: average score 2.51-3.25 for society; and Level 4: average score 3.26-4.00 for the rightness and goodness.

(3) For environmental volunteers test, there are 35 items of 5 options which are A, B, C, D and E, with the following scoring criteria on Boonchom (2002), Level 1: average score 1.00-1.80 means that the least amount of volunteers spirit; Level 2: average score of 1.81-2.60 means that a low level of volunteers; Level 3: average score of 2.61-3.40 means that the moderate volunteers; Level 4: average score 3.41-4.20 means that a high level of volunteers spirit; and Level 5: average score of 4.21-5.00 means that the highest level of volunteers.

(4) Bring the created tools sent to 5 experts to consider the consistency of the research tools to the objective. It found that knowledge test about waste and sewage management had an IOC value of 0.96. Environmental ethics test had an IOC value of 0.98. Environmental volunteers test had an IOC value of 0.97 . Showed that all questions are relevant for their content and purpose and can be used for data collection.

(5) Using the Research tools to try out with the $4^{\text {th }}$ year undergraduate students in Environmental Education program, Faculty of Environment and Resource Studies, Mahasarakham University in the $1^{\text {st }}$ semester of the academic year 2018, that is not a sample to find the difficulty, individual value of authority and the confidence of the whole version found that:

(5.1) The knowledge test about waste and sewage management had an appropriate level of difficulty: the lowest 0.40 and the highest 0.63 for the individual discrimination using criteria for classifying high and low groups analysis of the discriminant power for each item with a value of 0.20 and above. It was found that all questions were individual discretionary powers at the valid level, i.e., between $0.21-0.74$, and the whole confidence 
of the Cronbach's alpha coefficient method of knowledge test set to be value greater than 0.70 is considered a test with confidence and can be used in research. The results were found to be a confidence factor of 0.95 , indicating that all of the knowledge tests were compliant with the higher tolerances greater than 0.70 and could be used for data collection.

(5.2) The environmental ethics test has been found that all questions had the authority to classify each item in the applicable level, i.e., between 0.22-0.68 while the whole confidence value was found to be 0.90 , indicating that all environmental ethics test had higher confidence than the criterion and could be used for data collection.

(5.3) The environmental volunteers test has been found that all questions had the authority to classify each item in the applicable level, i.e., between $0.34-0.80$ while the whole confidence value was found to be 0.95 , indicating that all environmental volunteers test had higher confidence than the criterion and could be used for data collection.

(6) Take the research tools to improve as complete and then used to collect the data with the sample.

\subsection{Data Collection}

2.6.1 In the development of learning activities on waste and sewage management using question and problems-based learning, this research was conducted by using one-group pretest-posttest design research (Luan \& Angkhana, 2000) by conduct a knowledge test about waste and sewage management, environmental ethics and environmental volunteers before learning, then organized learning activities on waste and sewage management using question and problems-based learning and take a test after learning. The symbolic view of this design is given in Table 1.

Table 1. One-group pretest-posttest design research plan

\begin{tabular}{|l|l|l|l|}
\hline Sample Group & Pre-test & Treatment & Post-test \\
\hline E & $\mathrm{T}_{1}$ & $\mathrm{X}$ & $\mathrm{T}_{2}$ \\
\hline
\end{tabular}

Note. E: Experimental group; $\mathrm{T}_{1}$ : Pretest; X: Treatment (learning activities on waste and sewage management by using question and problems base learning); $\mathrm{T}_{2}$ : Posttest.

2.6.2 Prepare teaching materials, including learning activities plans on waste and sewage management using question and problems-based learning, knowledge test about waste and sewage management, environmental ethics test and environmental volunteers test. 
2.6.3 Take a pre-test with a sample of students by using a knowledge test about waste and sewage management, environmental ethics test and environmental volunteers test that the researcher has created.

2.6.4 Teach using a learning activity plan on waste and sewage management using question and problems-based learning with the 111 undergraduate students in Environmental Education program, Faculty of Environment and Resource Studies, Mahasarakham University in the $1^{\text {st }}$ semester of the academic year 2019 in control garbage and sewage course for a period of 1 semester (as showed in Table 2).

Table 2. Learning activity plans on waste and sewage management by using question and problems-based learning

\begin{tabular}{|l|l|l|}
\hline Week & Learning activity plans & Long-term (hours) \\
\hline 1 & $\begin{array}{l}\text { Introduce the learning activity plan, pretest for knowledge, environmental } \\
\text { ethics and environmental volunteers }\end{array}$ & 3 \\
\hline $2-3$ & Activity plan 1: General waste management & 6 \\
\hline 4 & Activity plan 2: Organic waste management & 3 \\
\hline $5-6$ & Activity plan 3: Recycling waste management & 6 \\
\hline $7-8$ & Activity plan 4: Hazardous waste and electronic waste management & 6 \\
\hline $9-10$ & Activity plan 5: Sanitary landfill waste management & 6 \\
\hline $11-12$ & Activity plan 6: RDF-waste power plant & 6 \\
\hline $13-14$ & $\begin{array}{l}\text { Activity plan 7: The master plan for solid waste management of the country } \\
\text { (2016-2021) }\end{array}$ & 6 \\
\hline 15 & Summary of learning activity plan on waste and sewage management & 3 \\
\hline 16 & Posttest for knowledge, environmental ethics and environmental volunteers & 3 \\
\hline Total & & 48 \\
\hline
\end{tabular}

The learning activities by using question and problems-based learning, the steps are as follows:

(1) Set up a problem, the researcher explains, introductory to let learners know how to teach and teach to formulate problems with the problem of waste management by presenting the current situation of solid waste that is an issue and is interesting to stimulate students' interest and discernment. For example, an instructor made a problem with "The problem of solid waste residue in the community area surrounding Mahasarakham University". The students analyze the problem together within the group to set the scope of work and define roles, duties and responsibilities of each person in the group. 
(2) Questioning cause and effect, researcher questions the cause and effect of the waste management problem. From the problem in item 1, the instructor asked the cause and effect of the problem of residual waste piled up around the waste storage waiting to be transported for disposal. Then the researchers deliver lectures on waste and sewage management which consists of 7 activity plans. During the lecture, the researchers set issues related questions throughout the lecture content and to test their knowledge during the learning activities of 10 questions.

(3) Discuss together to find solutions, researcher take time to study, brainstorm, think, analyze, understand the problem, link to identify the problem, causes and effects arising from solid waste. In the meantime, the instructor suggested help stimulate discussion within the group and insert principles of morality and ethics for learners to understand and analyze problems in order to find suitable answers leading to better environmental behavior practices.

(4) Synthesize problematic issues and answers, the students share information and knowledge gained from studying and research together. Discuss the results and synthesize the issues and answers to whether they are appropriate or not. Is the information sufficient to solve the problem?

(5) Summarize the lesson and evaluate the answer. All groups help to summarize the knowledge in the overall problem. The instructor and the learners assess their performance whether the answers they are studying are appropriate or not. And presenting works in various formats.

2.6.5 When teaching all 7 learning activities plans, take a post-test with knowledge test about waste and sewage management, environmental ethics and environmental volunteers which is the same set as the pretest.

2.6.6 Analysis test by statistical methods to test the hypothesis.

2.6.7 The effects of the development of learning activities plans on waste and sewage management using question and problems-based learning, was found that the learning activities plans on waste and sewage management was equal to $94.24 / 87.52$, which is higher than the set $80 / 80$ criteria and the effectiveness index of learning activities plan on waste and sewage management was 0.7562 , indicated that the student's learning progress increased by $75.62 \%$.

\subsection{Statistics Used in Data Analysis}

The statistics used to analyze data in this research, there are details as follows:

2.7.1 The basic statistics are mean, percentage, frequency and standard deviation.

2.7.2 The statistics to test the efficiency of the tools were the suitability of the learning activity plans on waste and sewage management, conformity index value, the difficulty of the test of knowledge about waste and sewage management. The discriminant power of the questionnaire, confidence value, process efficiency value $\left(E_{1}\right)$, result efficiency value $\left(E_{2}\right)$ and effectiveness index (E.I.). 


\section{Macrothink}

2.7.3 Statistics test results and hypotheses at the .05 level of statistical significance, namely Paired t-test One-Way, MANOVA One-Way, MANCOVA, Univariate Test and comparison of pairs according to Scheffe's method in One-Way ANOVA.

\section{Results}

The results of the development of the learning activities plans on waste and sewage management using question and problems-based learning be summarized as follows:

3.1 The effect of the study and comparison of the knowledge average score on waste and sewage management, environmental ethics and environmental volunteers of students before and after the learning activity on waste and sewage management using question and problems-based learning, it was found that (as shown in Table 3):

3.1.1 The undergraduate students had an average score of knowledge about waste and sewage management, before the learning (pretest) was overall at a medium level $(\bar{x}=34.18)$ and after the learning (posttest) was overall at the highest level $(\bar{x}=61.27)$. When comparing the knowledge average score of waste and sewage management before and after the learning (pretest-posttest), it was found that after learning, the undergraduate students had knowledge scores higher than before the learning statistical significance $(p<.05)$.

3.1.2 The undergraduate students had an average score of environmental ethics of the pretest overall learning at the relatives and friends level $(\bar{x}=2.34)$ and the posttest was overall at the society level $(\bar{x}=3.13)$. When comparing the environmental ethics average score pretest and posttest, it was found that the undergraduate students had average score on environmental ethics in the posttest higher than the pretest statistical significance $(\mathrm{p}<.05)$.

3.1.3 The undergraduate students had an average score of environmental volunteers in pretest overall at a low level $\left(x^{-}=2.35\right)$ and the posttest was overall at a high level $(x=3.85)$. When comparing the environmental volunteer scores, the pretest and the posttest, it was found that the undergraduate students have an average score of environmental volunteers in the posttest higher than the pretest statistical significance $(\mathrm{p}<.05)$. 
Table 3. The effect of the comparison of the knowledge average score on waste and sewage management, environmental ethics and environmental volunteers of students before and after the learning

\begin{tabular}{|l|l|l|l|l|l|l|l|l|l|}
\hline \multirow{2}{*}{ Item } & \multicolumn{3}{|c|}{ Pretest } & \multicolumn{3}{|c|}{ Posttest } & \multirow{2}{*}{$t$} & \multirow{2}{*}{$\mathrm{df}$} \\
\cline { 2 - 10 } & $\bar{x}$ & S.D. & Level & $\bar{x}$ & S.D. & Level & & \\
\hline Knowledge $(\mathrm{N}=60)$ & 34.18 & 3.31 & Medium & 61.27 & 2.30 & Highest & -73.270 & 110 & $.000^{*}$ \\
\hline Environmental ethics $(\mathrm{N}=4)$ & 2.34 & 0.26 & $\begin{array}{l}\text { For relatives } \\
\text { and friends }\end{array}$ & 3.13 & 0.28 & For society & 21.761 & 110 & $.000^{*}$ \\
\hline Environmental Volunteers (N = 5) & 2.35 & 0.24 & Low & 3.85 & 0.19 & High & -47.735 & 110 & $.000^{*}$ \\
\hline
\end{tabular}

Note. Statistically significant at the level of 0.05 . N: full score.

3.2 The effects of the comparison of the knowledge on waste and sewage management, environmental ethics and environmental volunteers of the undergraduate students with different gender using One-Way MANOVA. It was found that there were no different of undergraduate students' average score of knowledge about waste and sewage management, environmental ethics, environmental volunteers of undergraduate students with different gender. Therefore, analyzed one-way test of the covariance of average score of the knowledge of waste and sewage management, environmental ethics and environmental volunteers (posttest) of undergraduate students of different genders using pre-test scores as a covariate using (One-Way MANCOVA). It was found that there were no different (As shown in Table $4-5)$.

Table 4. The Results of comparing the variance of knowledge, environmental ethics and environmental volunteers of undergraduate students with different gender using One-Way MANOVA

\begin{tabular}{|l|l|l|l|l|l|}
\hline Test statistics & Value & Hypothesis df & Error df & F & $\mathrm{p}$ \\
\hline Pillai's Trace & 0.021 & 3.000 & 103.000 & $.745^{\mathrm{b}}$ & 0.527 \\
\hline Wilks' Lambda & 0.979 & 3.000 & 103.000 & $.745^{\mathrm{b}}$ & 0.527 \\
\hline Hotelling's Trace & 0.022 & 3.000 & 103.000 & $.745^{\mathrm{b}}$ & 0.527 \\
\hline Roy's Largest Root & 0.022 & 3.000 & 103.000 & $.745^{\mathrm{b}}$ & 0.527 \\
\hline
\end{tabular}


Table 5. One-way covariance of knowledge about waste and sewage management, environmental ethics and environmental volunteers of undergraduate students with different gender using pre-test scores is a common variable (One-Way MANCOVA)

\begin{tabular}{|l|l|l|l|l|l|l|}
\hline Independent Variable & Dependent Variable & SS & df & MS & F & p \\
\hline \multirow{3}{*}{ gender } & Knowledge about waste and sewage management & 9.331 & 1 & 9.331 & 1.770 & 0.186 \\
\cline { 2 - 7 } & Environmental ethics & 0.003 & 1 & 0.003 & 0.042 & 0.839 \\
\cline { 2 - 7 } & Environmental Volunteers & 0.113 & 1 & 0.113 & 3.073 & 0.082 \\
\hline
\end{tabular}

3.3 The effect of the comparison of the knowledge about waste and sewage management, environmental ethics and environmental volunteers of the undergraduate students with different GPA, the results showed as shown in Tables 6-8.

3.3.1 There was statistically significance different of knowledge score about waste and sewage management, environmental ethics and environmental volunteers of the undergraduate students with different GPA $(\mathrm{p}<.05)$. The Univariate test was then tested. It was found that there was statistical significance different knowledge score about waste and sewage management of the undergraduate students with different GPA $(\mathrm{p}<.05)$, while there were no different of environmental ethics and environmental volunteers scores $(p>.05)$.

3.3.2 The undergraduate students with low GPA had different knowledge about waste and sewage management from those with medium GPA, Low GPA students have different knowledge from students with high GPA and students with medium GPA have different knowledge from students with high GPA with statistical significance $(\mathrm{p}<.05)$.

Table 6. Comparing the variance of knowledge, environmental ethics and environmental volunteers about waste and sewage management of students with different GPA using One-Way MANOVA

\begin{tabular}{|l|l|l|l|l|l|}
\hline Test statistics & Value & Hypothesis df & Error df & F & p \\
\hline Pillai's Trace & 0.638 & 6.000 & 214.000 & 16.700 & $0.000^{*}$ \\
\hline Wilks' Lambda & 0.367 & 6.000 & 212.000 & $22.999^{\mathrm{b}}$ & $0.000^{*}$ \\
\hline Hotelling's Trace & 1.713 & 6.000 & 210.000 & 29.971 & $0.000^{*}$ \\
\hline Roy's Largest Root & 1.705 & 3.000 & 107.000 & $60.815^{\mathrm{c}}$ & $0.000^{*}$ \\
\hline
\end{tabular}

Note. Statistically significant at the level of 0.05 . 
Table 7. One-way covariance of knowledge, environmental ethics and environmental volunteers overall, before and after the learning of students with different GPA using pre-test scores is a common variable (One-Way MANCOVA)

\begin{tabular}{|l|l|l|l|l|l|l|}
\hline Independent Variable & Dependent Variable & $\mathrm{SS}$ & $\mathrm{df}$ & $\mathrm{MS}$ & $\mathrm{F}$ & $\mathrm{p}$ \\
\hline \multirow{5}{*}{ Grade Point Average (GPA) } & $\begin{array}{l}\text { Knowledge about waste } \\
\text { and sewage management }\end{array}$ & 365.889 & 2 & 182.944 & 90.632 & $0.000^{*}$ \\
\cline { 2 - 7 } & Environmental ethics & 0.064 & 2 & 0.032 & 0.402 & 0.670 \\
\cline { 2 - 7 } & Environmental Volunteers & 0.077 & 2 & 0.039 & 1.033 & 0.359 \\
\hline
\end{tabular}

Note. Statistically significant at the level of 0.05 .

Table 8. The results of comparing knowledge about waste and sewage management of the students with different GPA in pairs according to the Scheffe method

\begin{tabular}{|l|l|l|l|l|}
\hline \multirow{2}{*}{ GPA } & \multirow{x}{*}{$\bar{x}$} & Low & Medium & High \\
\cline { 3 - 5 } & & 57.93 & 60.30 & 63.00 \\
\hline Low & 57.93 & - & $.000^{*}$ & $.000^{*}$ \\
\hline Medium & 60.30 & - & - & $.000^{*}$ \\
\hline High & 63.00 & - & - & - \\
\hline
\end{tabular}

Note. Statistically significant at the level of 0.05 .

\section{Discussion and Conclusion}

The effects of the learning activity plans on waste and sewage management using question and problems-based learning be summarized and discussed as follows:

4.1 The results of the comparison of the knowledge about waste and sewage management, environmental ethics and environmental volunteers before and after learning, found that:

4.1.1 The undergraduate students had an average score of knowledge about solid waste and sewage management, environmental ethics and environmental volunteerism in the posttest higher than the pretest statistical significance. Because the researcher has developed a problem-based learning together with the question-based learning, asking questions to stimulate students' interest and answers. It is the use of current problems or as the main issue as the starting point of the cognitive thinking process and as a catalyst to develop group work skills. In which Thisana (2013) discussed the problem-based learning as a result of a process that aims to create understanding or find solutions to problems that bring problem situations as the starting point of the learning process. It is the information to decide on the appropriate solution and integrate with question based learning, the questions are an important technique 
in acquiring effective knowledge. It is a strategy that contributes to the development of thinking skills that lead to the learning process as well (Wattanaphon, 2008). Which the learning activities developed by the researcher were examined by experts and have appropriate action procedures. As a result, the learning activities plans are effective and the students have more learning progress. This is consistent with the findings of Esen and Neş'e (2014) found that the creative skills of students increased after learning through PBL. Evrim and Guzide (2020) found that students who are taught by PBL had the environmental knowledge scores higher than before learning and consistent with the findings of Supala, Poonsuk, and Thawatchai (2009) found that the students who were taught using the question-based teaching method combined with the question-based techniques have academic achievement in science after study higher than before study. So, it showed that learning activities on waste and sewage management using question and problems-based learning is appropriate and resulting in the advancement of learning.

4.1.2 The undergraduate students had environmental ethics about waste and sewage management after the learning higher than before the learning because the plans in each learning activity have been developed consists of 5 steps, Step 1: formulate the problem; Step 2: ask the cause and effect; Step 3: discussion for answers; Step 4: synthesize problems and answers; and Step 5: summary of the lesson. In which the question process, it is a question that relates to an actual issue today and affecting the daily life of the students. It is a stimulus for students to think for answers pointing out the benefits of the management of solid waste and sewage as well and the harm of environmental damage both for personal behavior and management which environmental ethics is as a guide to human behavior towards nature and the environment based on knowledge and understanding about nature (Amonrak, 2017). As well as Prayoon (2012) said that environmental ethics is inseparable from ethics, social life and community and compassion to treat the environment. And Prayoon and Prasart (2011) found that after studying environmental science in accordance with the National Qualifications Framework for Higher Education, students have environmental ethics higher than before studying. And Prachumporn (2019) found that the average score of environmental ethics after teaching with ethical instruction on environmental ethics development was higher than before teaching.

4.1.3 The undergraduate students had environmental volunteers about waste and sewage management after the learning higher than before the learning. As a result of volunteers is a process of cultivating consciousness leads to behavior that acts voluntarily, generously shared, not expecting returns through learning activities in creating volunteerism. In which all 7 learning activities were promoted and included environmental volunteer activities, behavior performed voluntarily. Volunteer spirit is an indicator of the psychological development of individuals who want to bring their potential to help others according to their own strength (Noppawan et al., 2010). It creates a mental subjects responsibility for themselves and society. May require application of theoretical concepts and processes developed a variety (Chaiwat, 2553) consistent with the findings of Prayoon et al. (2020) found that the senior high school at $\mathrm{Na}$ Chueak Pittayasarn School had mean score of volunteers post-training higher than the pre-training. And Prayoon et al. (2016) found that the students who studied by 
teaching environmental education using the flipped classroom teaching had environmental volunteers after learning more than before learning.

4.2 The effect of the comparison of the knowledge about waste and sewage management, environmental ethics and environmental volunteers of undergraduate students with different gender, found that:

4.2.1 The undergraduate students with different gender were no different of knowledge about waste and sewage management. As a result of all students, both female and male, received the 7 learning activities of waste and sewage management. The activity plans are an important means of transmission that will enable students to acquire knowledge according to their goals which the question and problems-based learning as learning that is student-centered, learner determine what they want to study. And all students are required to research and find solutions to specific problems (Tivawan, 2005). And knowledge is not just documented, but in work experience, processes, procedures and belief in the organization as well (Kirati, 2007) which is consistent with the study results of Thinkamchoet and Wongchantra (2018) found that youths with different genders were no different of knowledge about to natural resources and environment. And Kongporn, Thongchai, and Paitoon (2015) found that students with different genders when they attended a training on environmental law on waste management using a participatory learning process have no different of knowledge. And Suparat, Singseewo, Pinyoanunt, and Thamaseana (2010) found that the youths in Ban Khao Phra, Nakhon Nayok Province, that training guidelines for forest conservation and restoration with different genders have no different of knowledge. It showed that the undergraduate students with different gender have not effected on knowledge of waste and sewage management.

4.2.2 The undergraduate students with different gender were no different of environmental ethics about waste and sewage management. Environmental ethics are principles that should behave towards the environment. As a result, the environment is the existence of an ecological balance. The system does not lose its relationship with the environment (Prayoon, 2012). The human practiced on ethics, environmental responsibility because of a good sense of responsibility, having understanding of morals and goodness as a universal principle, selflessness, not to destroy the balance of nature, respect for the laws of nature will appreciate the environmental ethics that exists in itself (Charoen, 1998) which is consistent with the study results of Yang et al. (2019) found that students of different gender when engaging in environmental conservation activities with the school had no differences of knowledge and environmental ethics. And Sakorn (2012) found that students with different gender, were no different ethical behavior. And Kongporn, Thongchai, and Paitoon (2015) found that students with different gender were no different behaviors in waste management after the training. Therefore, it was shown that the male and female students who had completed the learning activities on waste and sewage management using question and problems-based learning as learning were no different of environmental ethics.

4.2.3 The undergraduate students with different gender were no different of environmental volunteers about waste and sewage management. As a result of volunteering is desirable 
behaviors that individuals act voluntarily. Volunteer is an indicator of the growth of the mind of the person who wants to bring their potential to help others by being their (Noppawan et al., 2010). The development of the public consciousness may require the application of a variety of theories, concepts and development processes to be applied to give learners the opportunity to think for themselves, gradually cultivate, the public consciousness naturally and sustainably (Chaiwat, 2010) which is consistent with the study results of Phra et al. (2018) found that learning management for volunteer to develop in social studies, religion and culture, there are no different volunteers of learners of male and female. And Prayoon et al. (2020) found that male and female students were no difference in environmental volunteers. Therefore, it was shown that the male and female students who had completed the learning activities on waste and sewage management using question and problems-based learning as learning were no different of environmental volunteers.

4.3 The effect of the comparison of the knowledge about waste and sewage management, environmental ethics and environmental volunteers of undergraduate students with different Grade Point Average (GPA), found that:

4.3.1 The undergraduate students with different GPA were different of knowledge about waste and sewage management. This is the result of the use of problems or questions as an important technique for effective knowledge acquisition. It is a teaching method that produces learning that develops thinking, interpretation, and conveying skills leading to change and improvement of the learning process as well. The question of motivation and stimulate the interest of students (Wandee, 2010). The define solving problem that are common to the real situation must be selected good problems and must be interesting and encourage students to discuss and learn at a deeper level to understand the concept of the problem rather than memorization (Wanlee, 2004) which consist with the study results of Prayoon (2009) found that the experimental group students with different GPA were different knowledge of the environment. And Phra and Piyaphong (2019) found that students with different educational levels after learning activity on solid waste management, they had different knowledge. And Maryam and Wisaka (2013) found that students with different grade were different knowledge of environmental conservation in schools. Therefore, it was shown that the undergraduate students with different GPA who had completed the learning activities on waste and sewage management using question and problems-based learning were difference of knowledge about waste and sewage management.

4.3.2 The undergraduate students with different GPA were no different of environmental ethics score about waste and sewage management. It is the result of effective waste and sewage management learning activities that the researcher has created. The media can be used in teaching knowledge in waste management as well enable students to modify behaviors that show concern for the environment. Human beings cannot live if environmental conditions are lost or degraded (Charoen, 1998). Humans are just part of the natural system has to adapt to natural system. Not aiming to adjust the natural environment to be a slave to serve human beings (Phra, 1998) which consist with the study results of Kongporn, Thongchai, and Paitoon (2015) found that students with different GPA, were no different in the waste handling behavior after the training in waste management. And Spinolo (2015) 
found that the environmental behavior of the 9th grade students in the school was not different. And Ratchakrit and Sukarnpicha (2014) found that the ethics of child teachers with educational background and working experience were different. There are no different of ethics. Therefore, it was shown that the undergraduate students with different GPA who had completed the learning activities on waste and sewage management by using question and problems-based learning as learning were no different of environmental ethics.

4.3.3 The undergraduate students with different GPA were no different of environmental volunteers about waste and sewage management. The learning activities on waste and sewage management are integrated learning that promotes cooperation in the group, analyze problems together. The sub-division is a method that allows students to brainstorm ideas and behaviors of each student. In addition, building self-confidence that will lead to volunteerism. It should be an activity that helps and do things that benefit others (Varaporn, Phrakaikaew, \& Wanna, 2008). Volunteers is the indication of the psychological development of individuals who want to bring their own potential to help others according to their strength. And when done, it affects happiness of the heart (Noppawan et al., 2010) which is consistent with the study results of Raweewan et al. (2018) found that students with different GPA, were no different opinions on teaching and learning to promote public consciousness. And Surasak and Prayoon (2018) found that the sample students with different GPA had no difference in environmental volunteer leadership skills. And Benjamas et al. (2018) found that students with different GPA had no differences in public consciousness. Therefore, it was shown that the male and female students who had completed the learning activities on waste and sewage management by using question and problems-based learning as learning were no different of environmental volunteers.

\section{Acknowledgements}

This research was successfully completed thanks to the great kindness and help from the field of Environmental Education, Faculty of Environment and Resource Studies, Mahasarakham University and financially supported by Graduate Development Plan, National Research Office and Foundation of Environmental Education for supporting research funding throughout the course.

\section{References}

Amonrak, S. C. (2017). Principles of teaching and learning and issues that should be included in the management of teaching and learning in environmental education. MBU Education Journal, 5(2), 172-180.

Benjamas, P., Bongkot, T., \& Tirawats, P. (2018). Public mind in medical school: A comparison of $1^{\text {st }}-3^{\text {rd }}$ year medical students at faculty of medicine Vajira Hospital. Vajira Medical Journal: Journal of Urban Medicine, 62(4), 327-334. https://doi.org/10.14456/ vmj.2018.30

Boonchom, S. (1990). Preliminary research (2nd ed., p. 115). Suveiriyasarn Publisher, Bangkok. 
Boonchom, S. (2002). Preliminary research (7th ed., p. 103). Bangkok: Suveiriyasarn Publisher.

Chaiwat, S. (2010). Teach children to have a public mind (p. 52). Bangkok: We Print Publisher.

Charoen, C. (1998). Environmental ethics concept a comparative study of Western theories with Theravada Buddhism (pp. 66-70). Nakhon Pathom: Mahidol University.

Esen, E., \& Neş'e, B. (2014). The effects of problem-based learning method in higher education on creative thinking. Procedia-Social and Behavioral Sciences, 116(21), 3494-3498. https://doi.org/10.1016/j.sbspro.2014.01.790

Evrim, U., \& Guzide, D. (2020). The Effect of problem-based learning on 7th-grade students' environmental knowledge, attitudes, and reflective thinking skills in environmental education. Journal of Education in Science, Environment and Health, 6(3), 177-192. https://doi.org/10.21891/jeseh.705145

Jiranoot, T., \& Prayoon, W. (2018). The development of camp on natural resources and environmental sonservation in the ASEAN for youths in Roi-et province. International Journal of Agricultural Technology, 14(7), 2077-2096.

Kirati, Y. (2007). Organization knowledge management and case studies (p. 21). Bangkok: Mr. Copy (Thailand) Co., Ltd.

Kongporn, N., Thongchai, N., \& Paitoon, S. (2015). Development of environmental law training in solid waste management for students in the community along the canal (pp. 93-108). 6th Academic Conferences and Presentations of National and International Research, Humanities and Social Sciences.

Luan, S., \& Angkhana, S. (2000). Educational research techniques (3rd ed., p. 249). Bangkok: Suveiriyasarn Publisher.

Maryam, J., \& Wisaka, P. (2013). Knowledge, understanding guideline for environmental conservation in school: A case study of students in secondary school of Thamvitya Foundation School Yala. Al-Hikmah Journal of Yala Islamic University, 3(5), 39-50.

Noppawan, T., et al. (2010). Participatory action research of elderly people with volunteer mind in the elderly club to promote health and prevent health problems of the elderly, Phra Nakhon Si Ayutthaya Province (pp. 35-36). Research Grants from the National Research Council of Thailand, Phranakhon Si Ayutthaya Rajabhat University.

Patcharee, S. (2008). The development of learning provision model in social psychology by using community and experience as bases to promote characteristics of satisfying graduates. Journal of Behavioral Science, 14(1), 33-47.

Phra, M. P., Boonlert, C., \& Somchai, S. (2018). Learning management for developing volunteer learners in social studies, religion and culture at the high school. Phon Phisai District, Nong Khai Province. Journal of Educational Review, 5(1), 135-146. 


\section{I Macrothink}

Journal of Educational Issues

ISSN 2377-2263

2021, Vol. 7, No. 1

Phra, T. C., \& Piyaphong, C. (2019). Organization of learning activities about "Solid Waste Management" for enhancing senior elementary students' knowledge, awareness, and engagement in municipal solid waste management: A case of Wat Changron School, Ratburana District, Bangkok. E-Journal of Education Studies, 2(1), 1-18.

Pimpan, D. (2002). Behavior of science teaching (p. 29). Bangkok: Institute Academic Development (AID). Co., Ltd.

Prachumporn, L. (2019). Effects of the teaching by ethics insertion to environmental ethics development in undergraduate students. Academic Journal of Community Public Health, 5(1), 114-121.

Prayoon, W. (2009). The Buddha's Method of Teaching Ethics. University of the Thai Chamber of Commerce Journal, 29(3), 159-168.

Prayoon, W. (2012). Environmental Science (pp. 171-172). Mahasarakham: Mahasarakham University.

Prayoon, W. (2016). Environmental Education (pp. 105-110). Mahasarakham: Kakayia Publisher. https://doi.org/10.1002/he.20164

Prayoon, W., \& Prasart, N. (2011). Effects of environmental ethics infusion instruction on knowledge and ethics of undergraduate students. Research Journal of Environmental Sciences, 5(1), 77-81. https://doi.org/10.3923/rjes.2011.77.81

Prayoon, W., Kuantean, W., Surasak, K., Suparat, O., Likit, J., Kanika, S., \& Uraiwan, P. (2020). The development of environmental volunteer spirit for high school students. Environmental Research Journal, 14(01), 19-22. https://doi.org/10.36478/erj.2020.19.22

Ratchakrit, P., \& Sukarnpicha, P. (2014). Ethical study of teachers of special needs and normal children in demonstration schools Suan Sunandha Rajabhat University (Primary). Graduate Studies Online Journal, 1-3.

Raweewan, W., Somchai, S., \& Phra, W. (2018). Learning and teaching management for promoting the public mind of the 3rd grade secondary school students in Donmuang Thaharnagardbumroong School; Donmuang, Bangkok. Journal of Educational Review, 5(1), 89-103.

Sakorn, P. (2012). The moral behavior of Loei Rajabhat University students. Research and Development Journal, 7(21), 23-34.

Spinolo, H. (2015). Environmental literacy comparison between students taught in Eco-schools and ordinary schools in Madeira Island region of Portugal. Science Education International, 26(3), 392-413.

Supala, T., Poonsuk, U., \& Thawatchai, T. (2009). Effects of inquiry teaching method with questioning technique on critical thinking abilities and science learning achievements of Prathomsuksa 5 students. Rusamilae Journal, 30(2), 35-42. 
Suparat, B., Singseewo, A., Pinyoanunt, B., \& Thamaseana, P. (2010). A Study and development on knowledge attitude and practice in forest conservation and reforestration of youth in Ban Khao Phra community Nakhon Nayok Province. The Social Sciences. Medwell Journals, 5(6), 554-558. https://doi.org/10.3923/sscience.2010.554.558

Surasak, K., \& Prayoon, W. (2018). Development of environmental volunteer leadership training curriculum. Research and Development Health System Journal, 11(3), 582-596.

The Office of the Education Council. (2007). Management of problem-based learning (pp. 2-3). Office of the Education Council Secretariat, Ministry of Education, Bangkok.

The Secretariat of the House of Representatives. (2019). Solid waste management in Thailand (p. 1). Secretariat of the House of Representatives Publishing Office.

Thisana, K. (2013). Teaching Science: Knowledge for effective learning process (17th ed., pp. 137-138). Bangkok: Chulalongkorn University.

Tivawan, J. (2005). A Study on science learning achievment and communication skill by using problems-based learning/PBL (p. 8, Master's Project, M.E.D. (Secondary Education), Graduate School, Srinakharinwirot University, Bangkok).

Varaporn, W., Phrakaikaew, T., \& Wanna, P. (2008). Development of Volunteer Building Process of Boromarajonani College of Nursing Chiang Mai Students (Research Report). Chiang Mai: Boromarajonani College of Nursing, Chiang Mai.

Wandee, T. (2010). Clinical Teaching: Questioning (Using teaching questions) (p. 3). Faculty of Nursing, Department of Internal Medicine Nursing, Mahidol University.

Wanlee, S. (2004). Problem-based learning, learner-centered learning model, Bangkok (p. 71). Booknet Publisher.

Wattanaphon, R. (2008). A student-centered instructional management manual (pp. 20-25). Nakhon Ratchasima: Rajamangala University of Technology Isan.

Yang, C. Y., Charin, M., \& Jarunee, M. (2019). Literacy and Environmentally Ethical Behaviors of Secondary School Students in China. Journal of Graduate MCU KhonKaen Campus, 6(3), 137-151.

Yosawee, I. (2011). Problem Based Learning Development (PBL) (p. 1). Suan Dusit Rajabhat University, Bangkok, Thailand.

\section{Copyright Disclaimer}

Copyright for this article is retained by the author(s), with first publication rights granted to the journal.

This is an open-access article distributed under the terms and conditions of the Creative Commons Attribution license (http://creativecommons.org/licenses/by/3.0/). 